\title{
Sea surface temperature variability in the subpolar Atlantic over the last two millennia
}

\author{
M.-A. Sicre, ${ }^{1}$ I. R. Hall, ${ }^{2}$ J. Mignot, ${ }^{3}$ M. Khodri, ${ }^{3}$ U. Ezat, ${ }^{1}$ M.-X. Truong, ${ }^{1}$ J. Eiríksson, ${ }^{4}$ \\ and K.-L. Knudsen ${ }^{5}$ \\ Received 12 May 2011; revised 24 September 2011; accepted 27 September 2011; published 13 December 2011.
}

[1] A decadal resolution time series of sea surface temperature (SST) spanning the last two millennia is reconstructed by combining a proxy record from a new sediment sequence with previously published data from core MD99-2275, north of Iceland. The alkenone based SST reconstruction is validated with historic observational data and compared to a new similar temporal resolution reconstruction obtained from sediment core RAPiD21-3K, in the subpolar North Atlantic. The two SST paleorecords show consistent multidecadal scale coolings throughout the interval and similar expressions during the contrasted climatic periods 'colloquially known' as the Medieval Climatic Anomaly (MCA) and Little Ice Age (LIA). In order to further understand the temporal and spatial SST variations and investigate the influence of natural forcings on the observed SST changes during the last millennium, we compare our time series to simulations using the Institut Pierre-Simon Laplace IPSLCM4-v2 climate model. This comparison highlights the potential importance of volcanism as a natural forcing driving coherent abrupt cooling events captured in the subpolar North Atlantic records.

Citation: Sicre, M.-A., I. R. Hall, J. Mignot, M. Khodri, U. Ezat, M.-X. Truong, J. Eiríksson, and K.-L. Knudsen (2011), Sea surface temperature variability in the subpolar Atlantic over the last two millennia, Paleoceanography, 26, PA4218, doi:10.1029/ 2011 PA002169.

\section{Introduction}

[2] High-resolution paleoproxy reconstructions from marine archives are crucial to improve our understanding of the ocean variability (decadal to centennial) and the role of external forcings (solar, volcanism and $\mathrm{CO}_{2}$ ) in climate change. Recent marine studies utilizing sediment cores recovered from high accumulation rate settings have achieved temporal resolutions that allow the investigation of sub-decadal timescale ocean variability [e.g., Cronin et al., 2003; Lund and Curry, 2004; Boessenkool et al., 2007; Sicre et al., 2008a, 2008b; Massé et al., 2008; Richter et al., 2009; Hall et al., 2010]. These time series not only improve our capability to describe the climate/ocean variability at key time-scales of the ocean/atmosphere dynamics, but also allow comparisons with General Circulation Model (GCM) simulations. The last millennium is of interest because it encompasses the contrasted periods of the warm era of the Medieval Climatic Anomaly (MCA) [Lamb, 1965] followed by a period of

\footnotetext{
${ }^{1}$ Laboratoire des Sciences du Climat et de l'Environnement, IPSL-CNRS, Domaine du CNRS, Gif-sur-Yvette, France.

${ }^{2}$ School of Earth and Ocean Sciences, Cardiff University, Cardiff, UK.

${ }^{3}$ Laboratoire d'Océanographie et du Climat: Expérimentation et Approches Numériques, IPSL-UPMC/CNRS/IRD/MNHN, Paris, France.

${ }^{4}$ Earth Science Institute, University of Iceland, Reykjavik, Iceland.

${ }^{5}$ Department of Earth Sciences, University of Aarhus, Aarhus C, Denmark.
}

Copyright 2011 by the American Geophysical Union. 0883-8305/11/2011PA002169 climate deterioration between the sixteenth to nineteenth century, known as the Little Ice Age (LIA) [Matthes, 1939], and the recent warming of the 20th century, to explore causes of ocean-climate variability.

[3] To produce proxy records resolving ocean variability at multidecadal to decadal time-scales, undisturbed highsedimentation rate and well-dated marine sediment cores are critical sources of information. Equally important is the choice of geographical location; areas sensitive to hydrographic or atmospheric changes are key regions to capture well-expressed signals of variability and abrupt changes. While variations in atmospheric boundaries such as the Inter-Tropical Convergence Zone (ITCZ) have provided information on large-scale ocean/atmosphere interactions [e.g., Haug et al., 2001], oceanic boundaries or frontal systems in the North Atlantic provide key sites to assess the variability of the Atlantic Meridional Overturning Circulation (AMOC). The AMOC is indeed an important and active component of the global climate system [e.g., Rahmstorf, 2003].

[4] This study presents new data from a gravity core from the North Icelandic margin which allows extending to the present-day the decadal-scale alkenone based SST reconstruction of the last two millennia from sediment core MD992275 earlier published by Sicre et al. [2008a, 2008b]. A new alkenone SST reconstruction from a gravity core recovered at a deeper site located on the Gardar Sediment Drift in the subpolar North Atlantic, south of Iceland was also generated to explore the decadal variability of the subpolar gyre (SPG), which is an important component of the global/large scale 


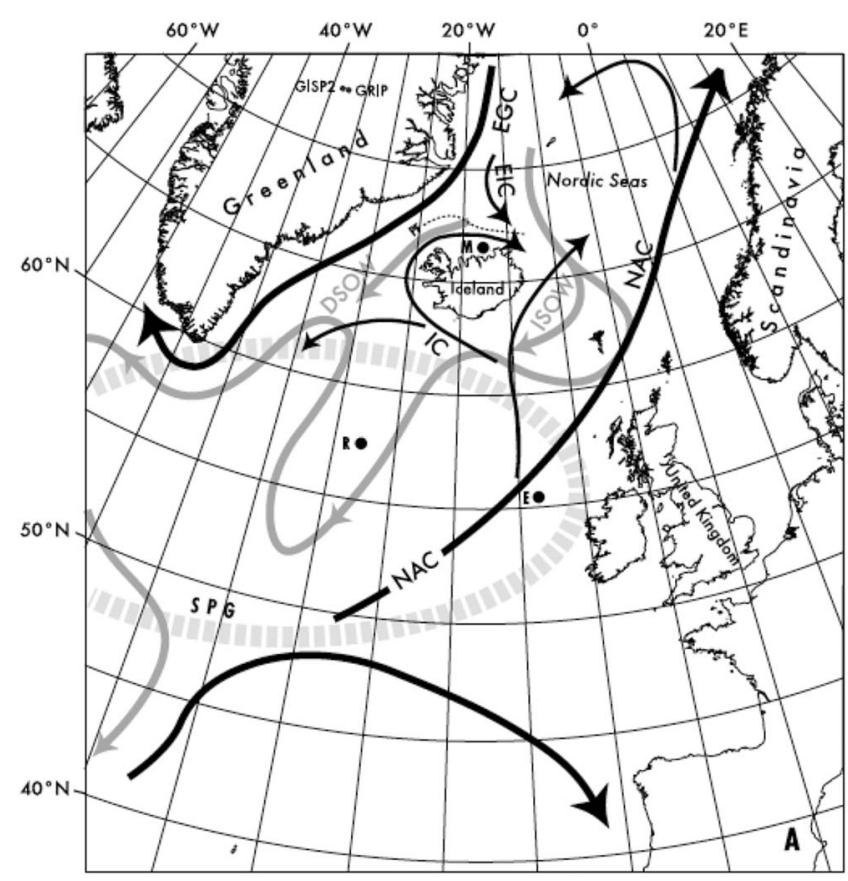

Figure 1. Map of the core site locations. Modern oceanographic system in the northern North Atlantic oceanography, with the surface water currents (black; modified after Hurdle [1986]) and bottom water overflow currents (gray) [after Hansen and Østerhus, 2000; Jonsson and Valdimarsson, 2004], and location of the studied cores. SPG, Sub Polar Gyre (stippled); NAC, North Atlantic Current; IC, Irminger Current; EGC, East Greenland Current; EIC, East Icelandic Current; DSOW, Denmark Strait overflow water; ISOW, Iceland Scotland overflow water; PF, Oceanographic Polar Front; M, MD99-2275; R, RAPiD 21-3K; E, ENAM9606.

circulation. Together our data are discussed with already published data in the subpolar Atlantic and the results of a simulation of the last millennium performed with the Institut Pierre Simon Laplace Coupled Model, IPSLCM4-v2.

\section{Study Sites}

[5] To extend the MD99-2275 SST record $\left(66^{\circ} 33^{\prime} \mathrm{N}\right.$; $17^{\circ} 42^{\prime} \mathrm{W}, 470 \mathrm{~m}$ water depth) published by Sicre et al. [2008a] to present-day, the box core B05-2006-GBC03C and gravity core B05-2006-GC05 (hereafter called GBC03 and GC05, respectively) were recovered during the R/V Bjarni Scemundsson cruise number B05-2006 of the EU European Climate of the Last Millennium project. Both cores were collected from the same location as MD99-2275. This site (Figure 1) is located within the polar front zone, where the cold and low-salinity waters of the East Greenland Current (EGC) and East Icelandic Current (EIC) meet with the warmer and saltier waters of the Northern branch of the Icelandic Irminger Current (IC), a bifurcation of the North Atlantic Current (NAC) [e.g., Østerhus et al., 2005]. Today, summer surface temperatures in this area are $\sim 6-8^{\circ} \mathrm{C}$.

[6] Sediment core RAPiD 21-3K was collected with a $15 \mathrm{~cm}$-square kasten corer of Zangger and McCave [1990]. It was recovered from the southern Gardar Drift $\left(57^{\circ} 27.09^{\prime} \mathrm{N}, 27^{\circ} 54.53^{\prime} \mathrm{W} ; 2630 \mathrm{~m}\right.$ water depth) on the eastern side of the Reikjanes Ridge during RRS Charles Darwin Cruise CD159 in 2004 for the UK NERC RAPiD Climate Change Programme [McCave, 2005]. The cruise specifically targeted high-sedimentation rate sites in the subpolar North Atlantic, and the RAPiD 21-3K site provides expanded sedimentary sequences suitable for high temporal resolution studies of surface ocean conditions related to the SPG and because of greater water depth it also allows reconstruction of past deep ocean circulation changes [Boessenkool et al., 2007; Hall et al., 2010]. It is located close to the modern position of the subpolar front, which develops along the SPG eastern boundary in the Iceland Basin, where it meets the North Atlantic Current (NAC) and separates cold subpolar water from warm Atlantic water [Hopkins, 1991; Flatau et al., 2003]. Today mean spring-summer temperatures at these latitudes are $\sim 10^{\circ} \mathrm{C}$, decreasing toward the north as heat from the ocean is supplied to the atmosphere, and the surface waters gradually mix with Arctic and Polar water masses.

\section{Methods}

[7] SSTs were estimated from sedimentary alkenone concentrations. These biomarkers are mainly produced today by the autotrophic coccolithophorid Eumiliana huxleyi inhabiting near-surface waters. Following their discovery [Boon et al., 1978], culture experiments and a limited number of field data from the northeastern (NE) Pacific demonstrated that the degree of unsaturation of the $\mathrm{C}_{37}$ alkenones, $\mathrm{U}_{37}^{\mathrm{K}^{\prime}}$, is controlled by algal growth water temperatures [Prahl and Wakeham, 1987]. The original calibration of Prahl et al. [1988] has been confirmed by the recent compilation of almost 700 water samples form the world ocean by Conte et al. [2006], improving SST estimates for the cold and warm ends of the temperature range. As opposed to temperature proxy calibration such as transfer functions that rely on regional databases, the alkenone calibration applies to the global ocean, regardless of the geographical location of the study site.

[8] The sediment cores were continuously sampled at $1-\mathrm{cm}$ step intervals except for the 2 uppermost cms of box core GBC03, which were sampled every $0.5 \mathrm{~cm}$. About $1-2$ grs of sediment were placed in a freeze-drier over night to remove their water content. The alkenones were then extracted from the freeze-dried sediment in a mixture of methanol/ methylene chloride $(1: 2 \mathrm{v} / \mathrm{v})$ and isolated by silica gel chromatography following the protocol of Ternois et al. [2000]. Gas chromatographic analyses were performed on a Varian CX 3400 gas chromatograph equipped with a fused CP-Sil-5 silica capillary column $(50 \mathrm{~m} \times 0.32 \mathrm{~mm}$ i.d. $)$ and a flame ionization detector. Helium was used as carrier gas. The oven temperature program was slightly modified and set at a steeper ramp of $20^{\circ} \mathrm{C} \mathrm{min} \mathrm{m}^{-1}$, from 100 to $300^{\circ} \mathrm{C}$. Analytical precision obtained for $\mathrm{U}$ ratios after triplicate injections was calculated to be 0.01 unit ratio. $\mathrm{U}_{37}^{\mathrm{K}^{\prime}}$ index values were calculated from the following ratio $\left(\mathrm{C}_{37: 2}\right) /\left(\mathrm{C}_{37: 2}+\mathrm{C}_{37: 3}\right)$ and converted into SSTs using the calibration of Prahl et al. $[1988] \mathrm{T}=\left(\mathrm{U}_{37}^{\mathrm{K}^{\prime}}-0.039\right) / 0.034$.

\section{Age Models}

[9] For MD99-2275 and GC05, tephra markers from Icelandic volcanoes have been identified and correlated with 


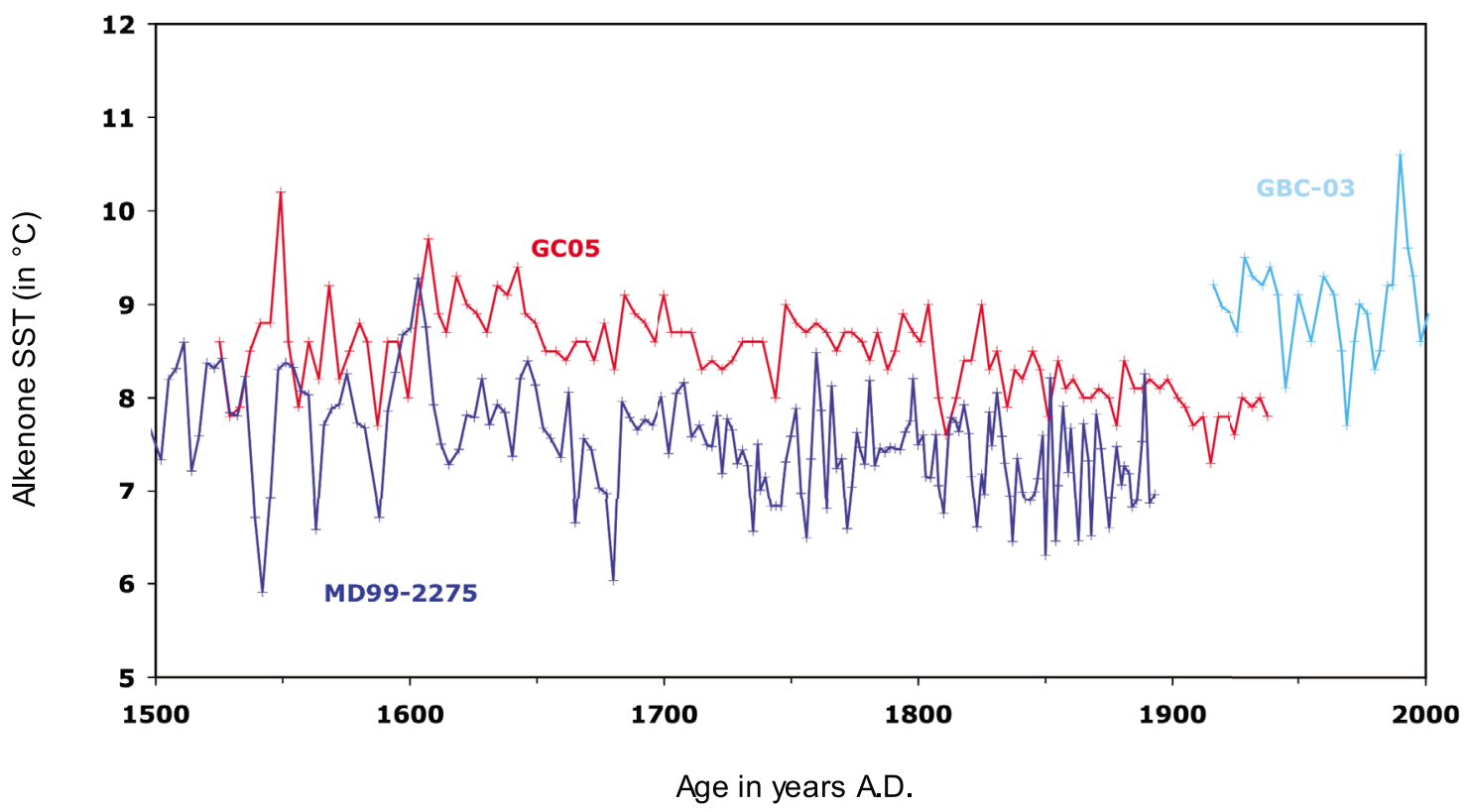

Figure 2. Sea surface temperature reconstructions based on alkenone unsaturation index $\mathrm{U}_{37}^{\mathrm{K}^{\prime}}$. SST reconstruction from the gravity B05-C2006-GC05 sediment (red line) and from the box core B052006-GBC03C sediment (light blue line). Dark blue line is the SST reconstruction from the Calypso MD99-2275 sediment expressed in the revised age model [cf. Eiríksson et al., 2011] of the upper part of the core, younger than 1717 A.D.

volcanic eruptions of known age, either from documentary sources or from terrestrially radiocarbon dated records. Reservoir effects were thus circumvented, allowing construction of a reliable tephrochronological age-depth model [Eiriksson et al., 2004, 2011]. In this study, we analyzed samples for a gravity core to complement earlier published data from a piston and box cores, filling the temporal gap between the two. Furthermore, Sicre et al. [2008a] previously estimated the MD core top age to approx. 1950 A.D. by extrapolation from the last tephra layer at 1717 A.D. identified at $\sim 100 \mathrm{~cm}$ depth to the top sediment. An additional tephra marker has subsequently been discovered in core MD99-2275 (at 1797 A.D.), and the age model has been revised accordingly and further improved with additional dating control provided by correlations with a dated gravity core - multicore pair from the same site. The current MD99-2275 age model is constructed using eight geochemically identified tephra layers [Knudsen et al., 2009, Table 2], the ${ }^{137} \mathrm{Cs}$ peak of maximum nuclear testing in 1963 A.D. and the top of undisturbed sediment according to ${ }^{210} \mathrm{~Pb}$ measurements. The top of the spliced cores at site MD99-2275 is assumed at 2006 \pm 1 A.D, and estimation of age model uncertainties for the record has been published [Eiriksson et al., 2011]. The revised age model of the uppermost portion of the MD99-2275 core now places the core top age at 1894 A.D. [Eiriksson et al., 2011; Ran et al., 2011]. For the box core, GBC03, age control is based on ${ }^{210} \mathrm{~Pb}$ data [Sicre et al., 2008b]. The age model constructed for site MD99-2275 yields age uncertainties between \pm 0.3 and $\pm 50 \mathrm{yr}$. The lowest age uncertainties occur at each tephra layer and larger age uncertainties in-between the tephra time markers.

[10] Because of the exceptionally high sedimentation rates of the North Icelandic margin area, i.e., $250 \mathrm{~cm} / 1000 \mathrm{yrs}$, sampling of the piston, gravity and box sediment cores at 1-cm interval resulted in a temporal resolution of 2-4 yrs, depending on changes in sedimentation rates at the coring site. Between tephra markers, linear sedimentation rates are assumed. The age uncertainty of a given tephra marker within the last millennium is typically a year or a few years, as the exact eruption dates are in most cases known from documentary sources. As for the North Iceland sediments, the RAPiD21-3K core was sliced continuously at $1-\mathrm{cm}$ intervals, but because of lower and variable sedimentation rates at this deeper site, sampling resulted in mean temporal resolution of $\sim 7.5 \mathrm{yrs}$. The age model is based on 12 AMS ${ }^{14} \mathrm{C}$ dates converted to calibrated years at $1 \sigma$ using the IntCal09 data set, as implemented by the CALIB 6.0 program [Stuiver and Reimer, 1993; Reimer et al., 2009], using a 400 year surface reservoir age (see Table S1). ${ }^{1}$ A thirdorder polynomial fit was used to derive the age-depth relationship so that an age could be assigned to each sample depth (see Figure S1).

\section{Results}

\subsection{Splicing SST Curves}

[11] Alkenone SSTs of the GBC03, GC05, as well as the last $400 \mathrm{yr}$ of the MD99-2275 core common to GC05, are shown in Figure 2, with no time scale adjustment. Note that the MD data are plotted in the revised age model compared to that of Sicre et al. [2008a], which shifts the SST values younger than 1717 A.D. (last tephra layer in the previous age model) toward older ages by a few years and places the top-

\footnotetext{
${ }^{1}$ Auxiliary materials are available in the HTML. doi:10.1029/ 2011PA002169.
} 


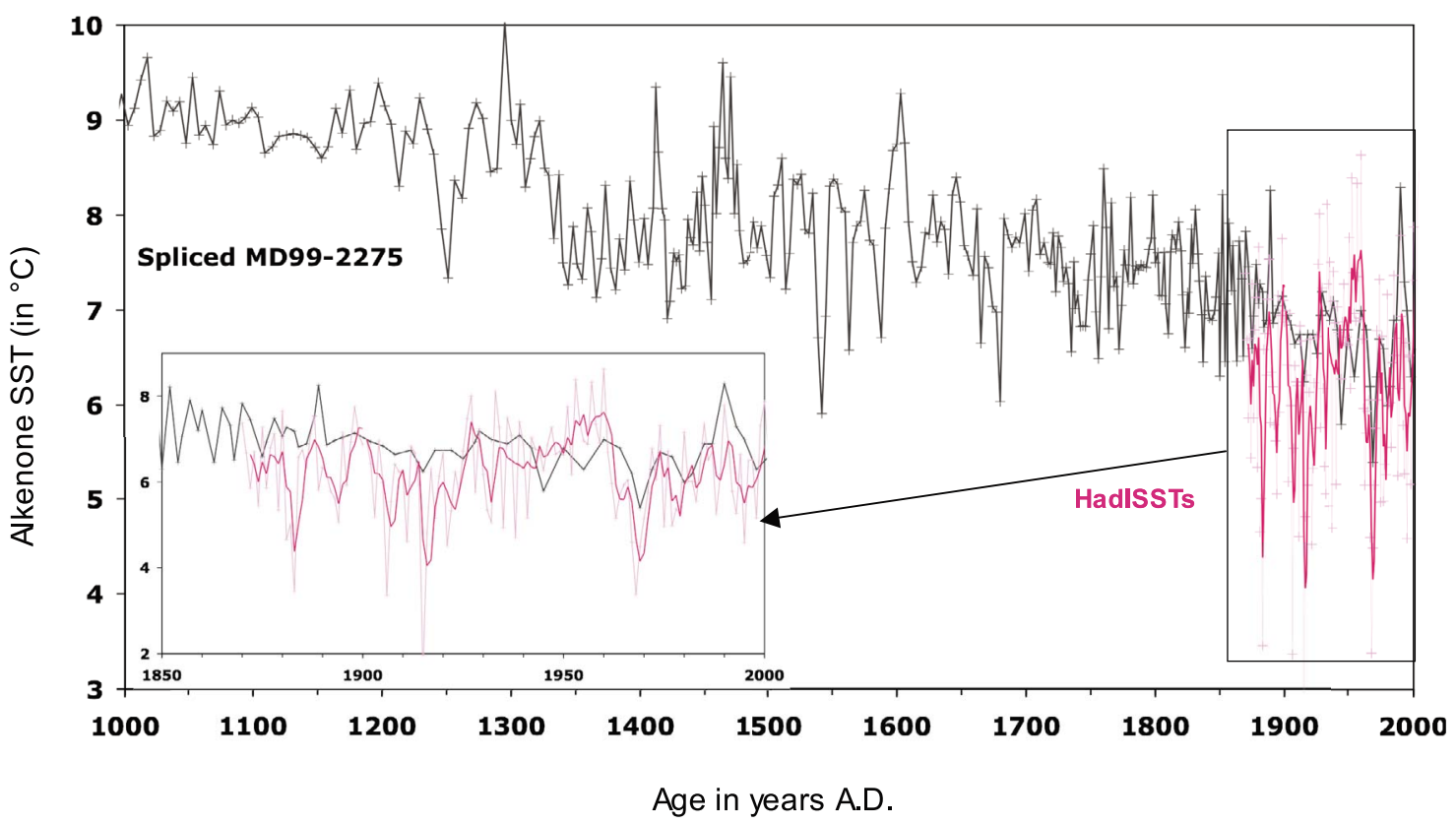

Figure 3. North Iceland spliced SST record at MD99-2275 site (black line) $\left(66^{\circ} 33 \mathrm{~N} ; 17^{\circ} 42 \mathrm{~W}, 470 \mathrm{~m}\right.$ water depth) and SSTs from the Hadley Data Center at the MD99-2275 grid point for July (pink line).

core age to 1894 A.D. [Eiriksson et al., 2011; Ran et al., 2011]. Despite a slight temporal relative offset of 2-5 yrs and the difficulty to compare multiannually resolved time series, the MD99-2275 and GC05 records show some resemblance. They both indicate decadal-scale fluctuations and a similar cooling trend toward present. Temporal variability thus appears reasonably well preserved in both time series. Nevertheless, the MD99-2275 record exhibits more detailed features and greater amplitude fluctuations than GC05, most likely because of the smoothing effect of the lower temporal resolution GC05 signal ( $\sim 3.5$ yrs as compared to mean 2.5 yrs in MD99-2275), and GC05 SSTs are offset toward higher values. A mean shift of $1.1^{\circ} \mathrm{C}$ was calculated by linear regression between the two curves over the overlapping period, 1600-1894 A.D. The GBC03 and GC05 SSTs indicate an additional mean offset of $1.3^{\circ} \mathrm{C}$ over the common 1925-1940 yr A.D. time interval. Differences between the SST reconstructions are not entirely unexpected given the highly spatial and temporal SST variability in this region. In fact, Hanna et al. [2006] reported strong regional differences between coastal sites around Iceland in observational data, especially those from northern Iceland, regularly influenced by winter and spring sea ice.

[12] The GBC03 and GC05 data were used to extend the MD99-2275 time series through the twentieth century after applying a correction to account for their respective SST offset relative to MD99-2275. More specifically, we first extended the MD99-2275 record, ending at 1894 yr A.D. to 1928 yr A.D., using the GC05 data from 1894 to 1928 yr A.D., corrected by a $1.1^{\circ} \mathrm{C}$ offset. From 1928 A.D. to 2001 yr A.D., we corrected the GBC03C SSTs by an additional $1.3^{\circ} \mathrm{C}$ offset. The composite SST curve obtained from the above procedure is shown in Figure 3. One important feature of this record is that the cooling that began at the onset of the LIA persisted during the twentieth century until 1969 A.D., which within the age model uncertainties, can be related to the Great Salinity Anomaly of the 1970s (GSA'70s). This period of increased sea ice in Greenland and Iceland seas, first observed in 19651971 A.D. NE of Iceland [e.g., Malmberg, 1969], would have been triggered by Arctic waters and sea-ice transport from Fram Strait that propagated in the northern North Atlantic [Belkin et al., 1998]. Post-GSA SSTs indicate warmer conditions, yet temperatures do not reach MCA estimates (average $\sim 9^{\circ} \mathrm{C}$ ) or show any increase similar to Northern hemisphere air temperatures [Mann et al., 2009]. The overall cooling trend depicted by our regional reconstruction is also seen in the recent Arctic 2 kyrs record as a result of slowly decreasing summer insulation at high northern latitudes [Kaufman et al., 2009]. However, the strong warming of the twentieth century in the Arctic contrasts with our oceanic record which does not clearly show this reversal, which might also possibly be dominated by multidecadal oscillations.

[13] For comparison, Figure 3 also shows the gridded Hadley Center SSTs (HadISSTs) $\left(67^{\circ} \mathrm{N} ; 18^{\circ} \mathrm{W}\right)$ in July, for which the best correlation with alkenone SSTs was obtained consistently with summer being the season of alkenone production at these latitudes [Sicre et al., 2002]. Considering the age model uncertainties, lower resolution of the proxy data as compared to the annually resolved July HadISST values, and the high spatial and temporal variability of this area, the composite SST reproduce quite well the decadal variations seen in the instrumental data especially after 1925. The mean SST estimate of $\sim 7^{\circ} \mathrm{C}$ calculated for the composite record between 1874 and 2001 is the same as the mean monthly value of $\sim 7^{\circ} \mathrm{C}$ in July from the neighboring site of Grímsey Island and slightly higher than mean July HadISSTs value of $\sim 5^{\circ} \mathrm{C}$, calculated for the 1874 to $2004 \mathrm{yr}$ A.D. period [see Hanna et al., 2006, Figure 5a]. However, during cold decades alkenone SSTs are biased toward warmer values (insert in Figure 3). This could reflect a weak representation 


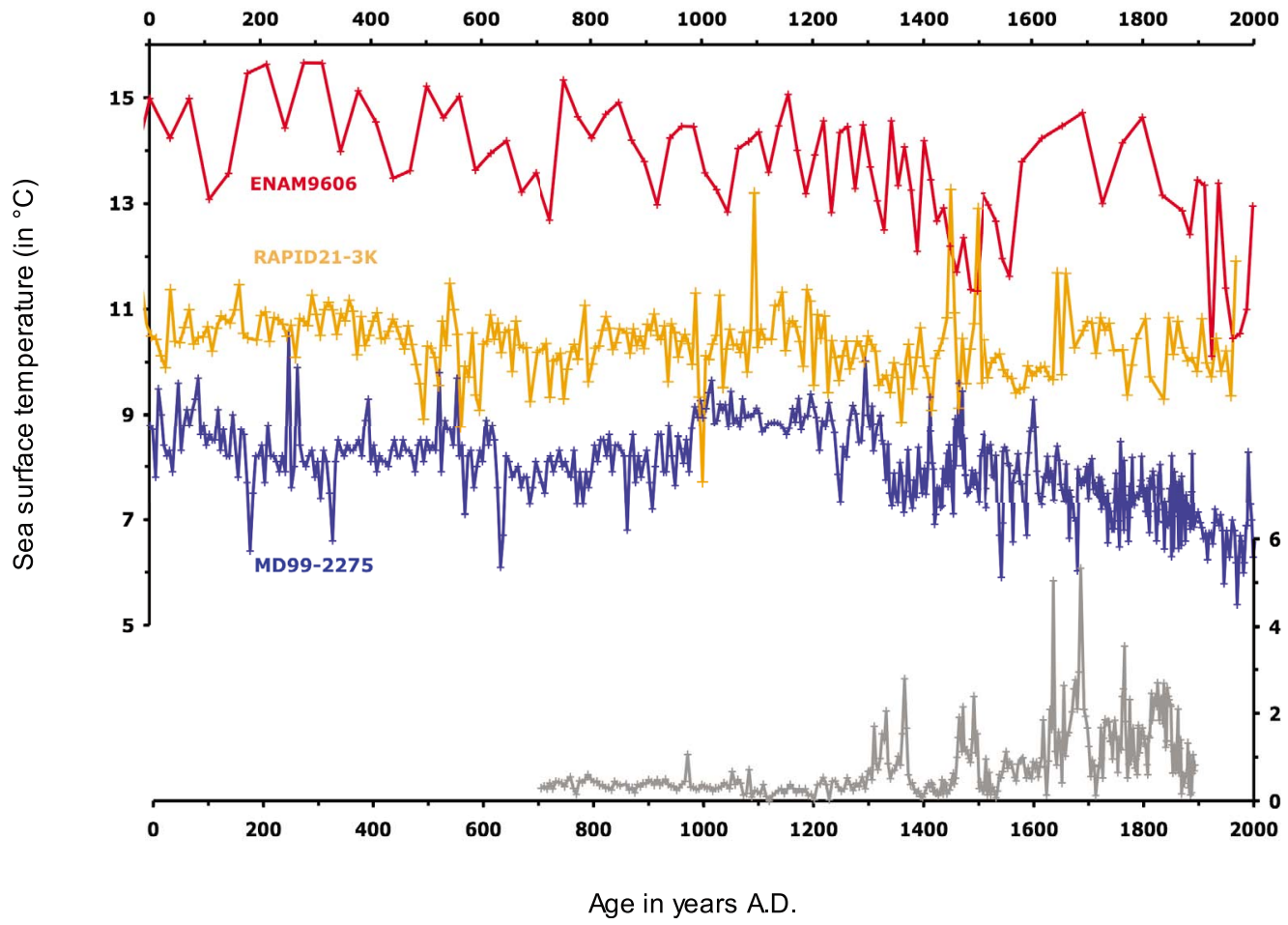

Figure 4. Comparison of the North Iceland spliced SST record at site MD99-2275 $\left(66^{\circ} 33^{\prime} \mathrm{N} ; 17^{\circ} 42^{\prime} \mathrm{W}\right.$, $470 \mathrm{~m}$ water depth) with alkenone-derived SSTs at Gardar Drift (RAPiD21-3K core, $57^{\circ} 27.09^{\prime} \mathrm{N}$, $27^{\circ} 54.53^{\prime} \mathrm{W} ; 2630 \mathrm{~m}$ water depth), and SST estimates obtained from $\mathrm{Mg} / \mathrm{Ca}$ analyses on Globigerina bulloides at Feni Drift, in the NE Atlantic (ENAM9606 core: $55^{\circ} 39^{\prime} \mathrm{N} ; 13^{\circ} 59^{\prime} \mathrm{W} ; 2543 \mathrm{~m}$ water depth) over the last 2000 yrs. The gray curve is the IP25 abundances from MD99-2275 (redrawn from Massé et al. [2008] in the revised age model).

of the polar front in the HadISSTs in a $1^{\circ} \times 1^{\circ}$ grid cell but may also suggest a shift of the alkenone production toward warmer summer months during "cold years," when the polar front reaches the core site. From these results, we can reasonably conclude that our reconstruction provides a reliable description of ocean temperature variability at multidecadal time-scales, north of Iceland. This study also reaffirms the robustness of the spatially based alkenone calibration established under modern climate conditions [Prahl et al., 1988; Conte et al., 2006], which is here for the first time 'validated' with a $100 \mathrm{yr}$ long instrumental time series. This new record combining three sediment sequences retrieved with different coring devices in a highly variable region thus represents a unique regional reconstruction benchmark.

\subsection{Comparison of RAPiD21-3K and MD99-2275}

[14] Alkenone-SSTs at Gardar Drift vary on average between 10 and $11^{\circ} \mathrm{C}$, i.e., $\sim 2^{\circ} \mathrm{C}$ higher than north of Iceland mean, as expected from the more southerly location of the RAPiD21-3K site (Figure 4). Temperatures show similar multidecadal to centennial scale variability between the two sites, which probably reflects regional variations in hydrographic properties of the NAC. The RAPiD21-3K core site is locate close to the subpolar front which tracks along the SPG boundary in the Iceland Basin, where it meets the North Atlantic Current (NAC) and separates cold subpolar water from warm Atlantic waters. SSTs derived from $\mathrm{Mg} / \mathrm{Ca}$ data in Globigerina bulloides calcite have recently been produced from a box core taken at the same site for the last $230 \mathrm{yrs}$ [Hall et al., 2010]. The average $\mathrm{Mg} / \mathrm{Ca}-\mathrm{SST}$ is $10.6^{\circ} \mathrm{C}$ and the total range of variation around $6^{\circ} \mathrm{C}$ likely due to changes in the calcification depths of $G$. bulloides. Smoothing the $\mathrm{Mg} / \mathrm{Ca}$ data to minimize seasonal/interannual variability in the record leads to decadal variability within a range of 9.5 to $11.5^{\circ} \mathrm{C}$ similar to the alkenone reconstruction over the sample period, suggesting that both proxy were recording mainly spring-summer surface water conditions.

[15] The MCA and LIA are well expressed in the North Icelandic record and likewise SSTs at Gardar Drift show a similar, albeit less distinct, MCA warming and cooling during the LIA. The long-term similarity at both sites during the MCA-LIA transition suggests a common regional forcing perhaps related to the footprint of sea ice on SSTs, possibly due to the influence of ice-bearing waters reaching as far south as the site of RAPiD21-3K on Gardar Drift, at least during the early stages of the LIA. As shown in Figure 4 (gray curve) the presence of sea ice at MD99-2275 has been detected since $\sim 1300$ yrs A.D. using the IP25 abundances $\left(\mathrm{C}_{25}\right.$ highly branched isoprenoid monounsaturated hydrocarbon), a proxy of seasonal sea ice [Belt et al., 2008]. Note that the IP25 data, first published by Massé et al. [2008], have been plotted using the MD99-2275 revised age model of Eiriksson et al. [2011], and thus now ends $\sim 1894$ A.D. During the LIA, sea ice becomes more 
frequent and persistent with more severe sea-ice conditions and pronounced cool excursions in the mid-fifteen, sixteen and seventeen centuries. At a regional scale, the similarity between sea-ice extent and the expansion of western European glaciers underlines the influence of sea ice on the European climate [Massé et al., 2008; Denton and Broecker, 2008]. In fact, several episodes of expansion of major Swiss Alp glaciers culminated in the mid-thirteenth, late sixteenth and mideighteenth centuries, coincide with decades of enhanced IP25 and lower SSTs north of Iceland. In a recent study, Lund et al. [2006] have shown that northward ocean heat transport during the LIA was reduced, possibly caused by buoyancy forcing in high latitudes, which would have contributed to the LIA cooling in the North Atlantic.

[16] We also compare our results with the 2 kyr SST record derived from $\mathrm{Mg} / \mathrm{Ca}$ on $G$. bulloides at Feni Drift, in the NE subpolar Atlantic (ENAM9606 core: $55^{\circ} 39^{\prime} \mathrm{N}$; $13^{\circ} 59^{\prime} \mathrm{W}$ ) published by Richter et al. [2009] (Figure 4). The temporal resolution of this sediment record ranges from 12 to $40 \mathrm{yrs}$ and thus allows comparison of multidecadal variability. Owing to its eastern location, on the main pathway of the North Atlantic inflow, the surface hydrography at ENAM9606 is influenced by the SPG and the subtropical gyre (STG), but also the Eastern North Atlantic Waters (ENAW), originating from the south. Surface water properties in this part of the North Atlantic strongly depend on the dynamics and spatial extent of the two gyres, with lower SSTs (and lower salinity) occurring under strengthened SPG gyre circulation and vice versa [Hatun et al., 2005]. Furthermore, a strong SPG has an east-west direction facilitating the intrusion of SPG waters into the eastern North Atlantic basin. Along most of the ENAM9606 record, SSTs are higher by about $3^{\circ} \mathrm{C}$ than at Gardar Drift, indicative of the stronger influence of the warmer STG waters. However, SSTs broadly decrease toward present except for 1550-1850 A.D. span, in which they increase abruptly from 11.5 to $14.5^{\circ} \mathrm{C}$ before declining to $\sim 10^{\circ} \mathrm{C}$ until near $1925 \mathrm{yr}$ A.D. This warming also heralds a less pronounced similarity with the MD992275 SSTs to the present. Following the SPG strength mechanism proposed by Hatun et al. [2005], the warm 1600 1800 A.D. period at Feni and Gardar drifts most likely alludes to a weak SPG and decreased contribution of cold waters, and/or increased STG influence. Recent Nd isotopic composition data on fossil deep-sea corals have shown generally lower proportions of SPG in mid-depth waters flowing through the Rockall Through into the Nordic Seas during the LIA as compared to the MCA, increasing into the twentieth century [Copard et al., 2011]. Based on the coincident high IP25 values recorded in core MD99-2275 (1600-1800 A.D.) and estimated spatial maximum sea-ice extent of Denton and Broecker [2008], we speculate that higher subpolar Atlantic SSTs and weaker SPG might be linked to the southwards migration of the polar front. Sea-ice advance linked to increasing upper ocean stratification may have reduced convection in the Labrador Sea and decreased SPG mixing of colder waters into the Atlantic inflow. This warming may have also provided enhanced moisture transport to western Europe feeding the glacier growth recorded during this interval. Since the early nineteenth century till about 1950 A.D., cooling at Feni drift points to a return to stronger SPG.

\subsection{Comparison With Model Simulations}

[17] In order to further understand the temporal and spatial SST variations and to infer conclusions on the impact of the natural external forcings on the observed SST changes we attempted to compare the last 1000 yrs segment of our SST time series to a simulation of the last millennium using the IPSLCM4-v2 climate model developed at the Institut PierreSimon Laplace [Marti et al., 2010]. This model couples the LMDz4 atmosphere GCM [Hourdin et al., 2006] and the ORCHIDEE 1.9.1 module for continental surfaces [Krinner et al., 2005] to the OPA8.2 ocean model [Madec et al., 1998] and the LIM2 sea-ice model [Fichefet and Maqueda, 1997], using the OASIS coupler [Valcke et al., 2000]. The resolution in the atmosphere is $3.75^{\circ}$ in longitude, $2.5^{\circ}$ in latitude, and 19 vertical levels. The ocean and sea ice are implemented on the ORCA2 grid (averaged horizontal resolution $2^{\circ} \times 2^{\circ}$, refined to $0.5^{\circ}$ around the equator, 31 vertical levels). In all simulations, the vegetation was set to a modern climatology from Myneni et al. [1997]. After a 110-year spin up with preindustrial greenhouse gas $(\mathrm{GHG})$ concentrations and tropospheric aerosols, forcing with a reconstruction of Total Solar Irradiance (TSI), GHG concentrations, changes in orbital parameters, and radiative effect of volcanic eruptions over the last millennium, from 850 to 2000 A.D., were included.

[18] For the TSI variability, we used the latest estimates of Solanki and Krivova [2006] and Krivova et al. (personal communication, 2009), which assume a $0.1 \%$ TSI decrease for the Maunder minimum compared to the modern minima, in good agreement with the calculations of Wang et al. [2005] (Figure 5a). These new TSI estimates are recommended by the third phase of the palaeoclimate modeling intercomparison project (PMIPIII) [Schmidt et al., 2011]. Note that the secular variability is rather weak compared to the more widely used TSI reconstruction as in the last Intergovernmental Panel on Climate Change [Lean, 2000; Bard et al., 2000; Crowley, 2000; Intergovernmental Panel on Climate Change (IPCC), 2007, chapter 6]. The largest tropical eruptions of the last millennium recorded in the polar ice cores [Gao et al., 2008] are also included in the model, since it is very likely that they did perturb climate on a global scale. Sulphate aerosols produced by large tropical eruptions are indeed transported poleward in the lower stratosphere of both hemispheres and can spread over the whole globe during the following two to three years [Robock, 2000]. In the present simulation, we imposed the sequence of tropical eruptions reconstructed by Gao et al. [2008] as stratospheric aerosol optical depths (AOD) (M. Khodri et al., manuscript in preparation, 2012) (Figure 5b). As discussed by Timmreck et al. [2009] for the ECHAM model, aerosol size typical of that observed for the Mount Pinatubo eruption does not apply for mega-eruptions. Nevertheless, in our model as well the volcanic module tends to overestimate the radiative effect of the mega eruptions because of the use, for paleo-eruptions, of aerosol effective radius and optical properties derived from observations over the instrumental period for Mount Pinatubo (1991) and El Chichon eruptions (1985). Together with a rather weak scaling for the TSI variations, this set-up might overestimate the effect of volcanism over the last millennium. Details of the oceanic response to volcanic events in this simulation is discussed by Mignot et al. [2011]. 


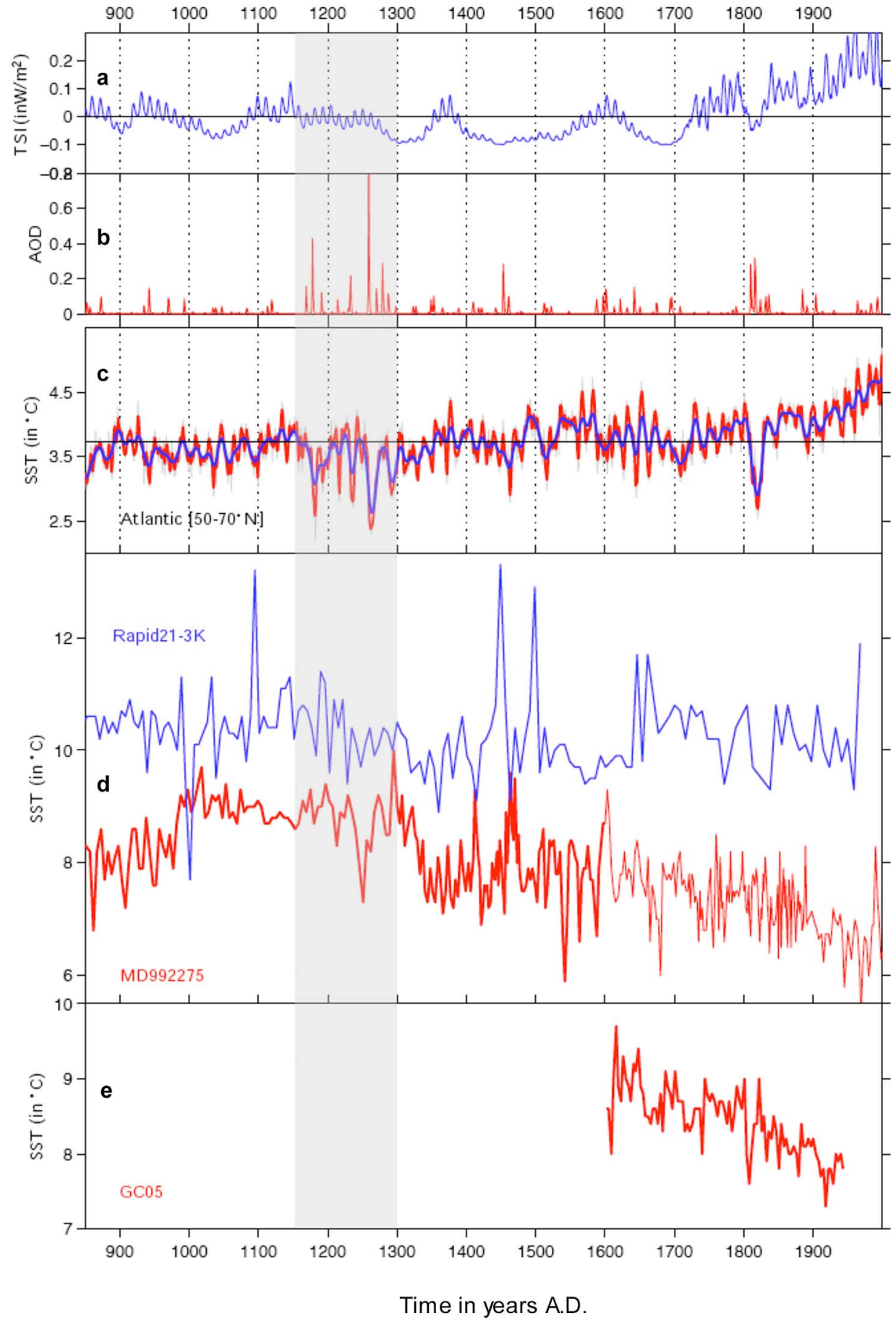

Figure 5. Data comparison to model simulation of the last 1000 yrs. Forcing from A.D. 850 to 2000 imposed in the IPSLCM4_v2 simulation (Figures 5a and 5b; see text for details). (a) Anomalous short wave input at the top of the atmosphere, taken as an estimation of variations of the total solar irradiance (TSI). (b) Imposed aerosol optical depth changes (AOD) in the stratosphere associated to volcanic eruptions. (c) Evolution of the SST averaged between 50 and $70^{\circ} \mathrm{N}$ in the North Atlantic. Raw annual mean data are shown in gray. Low-pass filtered data using a running mean of 3 yrs are shown in red. Low-pass filtered data using a spline function with a cutoff at $20 \mathrm{yrs}$ are shown in blue. (d) SST record for gravity core RAPiD21-3K (blue curve). Spliced SST record at the MD99-2275 site (red curve), off North Iceland. After 1600 A.D., thin line indicates the common portion with the gravity core B05-2006-GC05. (e) SST record of gravity core B05-2006-GC05. 
[19] The interannual standard deviation of SST over the pre-industrial period (A.D. 1000 to 1850) and over the model spatial grid along the northern coast of Iceland ranges from 0.62 to $0.72^{\circ} \mathrm{C}$. This compares well to the MD99-2275 proxy-based SST standard deviation which amounts $0.71^{\circ} \mathrm{C}$. Nevertheless, given potential model bias in resolving the detailed oceanography in this region, in particular the position of the polar front, we compare the proxies to SSTs calculated within a latitudinal band bracketing the study sites, i.e., 50 to $70^{\circ} \mathrm{N}$ over the Atlantic domain (Figure $5 \mathrm{c}$ ). The comparison of the modeled and proxy-based SSTs inferred from the highest resolved and robustly dated marine core composite, shows a similar range of decadal variability, with a peak-topeak amplitude of SST decadal variability ranging between 1 and $1.5^{\circ} \mathrm{C}$. As earlier discussed by Sicre et al. [2008a], the N. Iceland SST reconstruction reveals pronounced multidecadal variability, with dominant periods at 20-25 yrs and 50-150 yrs, which are also seen in the model (not shown). Our proxymodel comparison therefore reveals a remarkable overall coherency in terms of amplitude and frequency for the background decadal variability. Note that given the model biases and the difficulty to represent correctly the location of the polar front, it is difficult to compare modeled and proxy based SSTs on a finer scale that the area average presented here. This explains at least partly the lack of long-term cooling trend observed in MD99-2275. The model does not show either a step increase at the beginning of the MCA. Whether this is due to a model deficiency or the weak TSI variations is difficult to assess within the present study. The most striking feature of this comparison is the pronounced cooling centered at $\sim 1250 \mathrm{yr}$ A.D. in MD99-2275, which is also seen in the simulated SSTs at $\sim 1260$ yr A.D., in the northern North Atlantic domain. Comparison with the volcanic eruption times-series based on Gao et al. [2008] shown in Figure $5 b$, indicates a reasonably good temporal correspondence of these cooling patterns, within the age model uncertainty of the proxy reconstructions, with the largest volcanic eruption of the last 1500 yrs that occurred $\sim 1259$ yr A.D. Furthermore, looking into the structural details of this period we can identify, both in the model and proxy data (Figures 5c$5 d$ ), several distinct cold events of lower amplitude from roughly 1150 to 1260 A.D. preceding the largest SST drop of $>1{ }^{\circ} \mathrm{C}$ (gray area). For comparison, the standard deviation of the SST time series averaged over the same area in a millennium-long pre-industrial control simulation is $0.3^{\circ} \mathrm{C}$ (not shown). This nearly one century-long cold phase stands out from the background internal variability and appears consistent with the concomitant cluster of decadally paced volcanic eruptions. In the RAPiD21-3K data, this interval is also coincident with cooling SSTs, within the age uncertainty of the records, followed by the onset of deteriorating conditions toward the end on the MCA, 1350 A.D.

[20] In addition to the 1259 A.D. tropical eruption, two other major eruptive events occurred during the last millennium; the 1815 A.D. Tambora and, the smaller, 1453 A.D. Kuwae eruptions. The Tambora eruption is preceded by another eruption of similar amplitude ( 1812 A.D.) and followed by three small ones, while the Kuwae appears as a single main event, followed by a much weaker eruption. While cooling in response to the largest 1259 A.D. eruption sequence is well captured in MD99-2275 (Figure 4), the thermal effect of the
Tambora is barely discernable from the background variability. However, a clear decrease from $9^{\circ} \mathrm{C}$ to about $7.5^{\circ} \mathrm{C}$ that persisted almost $\sim 20 \mathrm{yrs}$ imprinted the GC05 record at the time of Tambora eruption (Figure 5e) and a similar duration $1-1.5^{\circ} \mathrm{C}$ cooling is also seen in RAPiD $21-3 \mathrm{~K}$, suggesting that the MD99-2275 site failed to record this event. As the sediment horizon corresponding to the Tambora eruption is predicted to occur at $45 \mathrm{~cm}$ below the core top within MD99-2275 it is plausible that the piston coring operation may have caused some disturbance of the upper most section [e.g., Skinner and McCave, 2003]. Such a problem is less likely to have occurred in the recovery of the gravity cores (GC05 and RAPiD 21-3K), which typically recovers a more intact near core top sediment.

[21] The amplitude of the simulated SSTs response to the 1453 A.D. Kuwae eruption occurring during the LIA is smaller than for the 1259 A.D. and Tambora eruptions. The rather weak and short-lived impact of this single large eruption in the model simulation of North Atlantic SSTs could explain why it is not observed in the proxy data. However, equally, local variability of the polar front during the LIA could make it more difficult to detect weaker externally forced short-lived cooling events at the MD99-2275 site. Furthermore, the nonlinear thermal response to volcanic eruptions is still an unexplained issue [e.g., Timmreck et al., 2009]. Instrumental data and earlier simulations have shown that the direct effect of volcanic eruptions is a decrease of global air temperature for a few years in response to increased reflection of solar radiation back to space by the aerosol layer, causing a negative radiative balance [Crowley, 2000], while their impact on the ocean can persist longer [Delworth et al., 2005; Stenchikov et al., 2009].

[22] Finally, even though some significant cold excursions recorded in our SST proxy reconstructions are not synchronous between sites or to large volcanic events, model-data comparison has helped identify climatic signals that stand out from the background variability in the proxy SST time series, and which might be related to the effects of volcanism, provided that the magnitude of the eruptive event is large and the temporal resolution of the sedimentary archives sufficient to reach multiannual to decadal time-scales. While we do not claim this forcing explains the whole climatic signal variability manifested in the proxy SST data, the model is instead used here to explore coherent cooling patterns in relation with known external climate forcing, in this case volcanism, and evaluate the response of surface ocean temperatures from marine records for which high-resolution data are almost inexistent.

\section{Conclusions}

[23] The MD99-2275 site SST record [Sicre et al., 2008a] was extended to the modern by combining marine sediment records obtained from different coring devices (box, gravity and piston corers) at the same site into a single composite record. The upper most portion of the spliced curve, covering the twentieth century, and which was missing in the earlier single MD99-2275 reconstruction, achieved a reasonable reproduction of regional instrumental data for this interval. Given that the hydrography at the site location north of Iceland is highly variable, both spatially and temporarily, this comparison gives us confidence in the reliability of our 
results. Comparison between the N. Iceland SST record and a similar resolution alkenone based SST record from sediment core RAPiD $21-3 \mathrm{~K}$ in the subpolar N. Atlantic shows that consistent multidecadal to centennial time-scale coolings occurred throughout the past millennium, and similar longer-term expressions of the MCA and LIA suggesting a strong connection between the two sites related to regional hydrography and the NAC. On the other hand, the continuous cooling into the twentieth century is a remarkable feature of the N. Iceland SST record, which underlines the importance of regional reconstructions for understanding long-term climate fluctuations.

[24] Comparison with the IPSL CM4-v2 model results for the last 1000 yrs also indicates a similar variability with pervasive multidecadal SST oscillations. Simulated and reconstructed SSTs, between about 1150 and 1300 yr A.D., highlight a series of decadal time-scale coolings of 1 to $2^{\circ} \mathrm{C}$, in response, at least in the model, to multiple eruptions with the most significant event occurring around $1259 \mathrm{yr}$ A.D., the largest eruptive event of the last 1500 yrs. The model-data comparison suggests that this sequence of closely spaced volcanic eruptions could be responsible for the cold spell that interrupted the warm MCA conditions north of Iceland. During the LIA, negative SST anomalies were also found subsequent to the 1453 A.D. Kuwae and 1815 A.D. Tambora eruptions in the simulated SSTs, but only cooling for the Tambora was detected in the gravity cores GC05 and RAPiD 21-3K, which ensure an intact upper sediment record. Note that the simulation does not show large-scale climatic shifts that could be compared to the MCA-LIA transition. Servonnat et al. [2010] discussed the difficulty to model this transition in a simulation including only the solar forcing. Details of the oceanic response to volcanic events in the IPSL model is discussed in a separate study [Mignot et al., 2011].

[25] Overall, this study demonstrates the value of highresolution reconstructions utilizing robust dating approaches, such as tephrochronology, for the detection of decadal-scale ocean variability and further, when combined with numerical simulations, to investigate the impact of discrete events such as volcanic eruptions.

[26] Acknowledgments. We are grateful to the French Polar institute IPEV for providing the IMAGES program the facilities during the IMAGES cruise in 1999 on the research vessel Marion Dufresne. We also thank the participants and crew of the R/V Bjarni Scemundson cruise in 2006 and RRS Charles Darwin Cruise CD159. The marine paleodata presented in this paper is a contribution of the PACTHOL project funded by the LEFE program supported by INSU (Institut National des Sciences de l'Univers) and CNRS for salary support, the EU-PACLIVA project (Pattern of Climate Variability in the North Atlantic) funded by the European Union 5th Framework Programme (contract EVK2-2002-00143) that initiated this research, and the Millennium project funded by the European Union 6th Framework Programme (contract EVK-CT-2006-017008) for providing additional samples at the MD99-2275 site. I.H. acknowledges the NERC RAPiD Climate Change Programme and was supported by grant NER/T/S/2002/00436. The modeling work using the IPSL-CM4 model was supported by the ANR ESCARSEL project and by the THOR project funded by the European Community's 7th framework program (FP7/2007-2013) under grant agreement GA212643 (Thermohaline Overturning - at Risk (THOR), 2008-2012). We appreciate constructive comments and suggestions from the three anonymous reviewers. This is LSCE contribution 4702.

\section{References}

Bard, E., G. Raisbeck, F. Yiou, and J. Jouzel (2000), Solar irradiance during the last 1200 years based on cosmogenic nuclides, Tellus, Ser. B, 52, 985-992, doi:10.1034/j.1600-0889.2000.d01-7.x.
Belkin, I. M., S. Levitus, J. Antonov, and S. A. Malmberg (1998), "Great Salinity Anomalies" in the North Atlantic, Prog. Oceanogr., 41, 1-68, doi:10.1016/S0079-6611(98)00015-9.

Belt, S. T., G. Massé, L. L. Vare, S. J. Rowland, M. Poulin, M.-A. Sicre, M. Sampei, and L. Fortier (2008), Distinctive ${ }^{13} \mathrm{C}$ isotopic signature distinguishes a novel sea ice biomarker in Arctic sediments and sediment traps, Mar. Chem., 112, 158-167, doi:10.1016/j.marchem.2008.09.002.

Boessenkool, K. P., I. R. Hall, H. Elderfield, and I. Yashayaev (2007), North Atlantic climate and deep-ocean flow speed changes during the last 230 years, Geophys. Res. Lett., 34, L13614, doi:10.1029/2007GL030285.

Boon, J. J., F. W. van der Meer, P. J. W. Schuyl, J. W. de Leeuw, P. A. Schenck, and A. L. Burlingame (1978), Organic geochemical analyses of core samples from Site 362, Walvis Ridge, DSDP Leg 40, in Deep Sea Drilling Project Initial Report, vols. 38, 39, 40, 41 Suppl., pp. 627-637, U.S. Gov. Print. Off., Washington, D. C.

Conte, M. H., M.-A. Sicre, C. Rühlemann, J. C. Weber, S. Schulte, D. Schulz-Bull, and T. Blanz (2006), Global temperature calibration of the alkenone unsaturation index $\left(\mathrm{U}_{37}^{\mathrm{K}^{\prime}}\right)$ in surface waters and comparison with surface sediments, Geochem. Geophys. Geosyst., 7, Q02005, doi:10.1029 2005 GC001054.

Copard, K., C. Colin, G. M. Henderson, J. Scholten, E. Douville, M.-A. Sicre, and N. Frank (2011), Late Holocene intermediate water variability in the northeastern Atlantic as recorded by deep-sea corals, Earth Planet. Sci. Lett., in press.

Cronin, M. T., G. S. Dwyer, T. Kamiya, S. Schwede, and D. A. Willard (2003), Medieval Warm Period, Little Ice Age and 20th century temperature variability from Chesapeake Bay, Global Planet. Change, 36, 17-29, doi:10.1016/S0921-8181(02)00161-3.

Crowley, T. J. (2000), Causes of climate change over the past 100 years, Science, 289, 270-277, doi:10.1126/science.289.5477.270.

Delworth, T. L., V. Ramaswamy, and G. L. Stenchikov (2005), The impact of aerosols on simulated ocean temperature and heat content in the 20th century, Geophys. Res. Lett., 32, L24709, doi:10.1029/2005GL024457.

Denton, G. H., and W. S. Broecker (2008), Wobby ocean conveyor circulation during the Holocene?, Quat. Sci. Rev., 27, 1939-1950, doi:10.1016/j. quascirev.2008.08.008

Eiríksson, J., G. Larsen, K. L. Knudsen, J. Heinemeier, and L. Símonarson (2004), Marine reservoir age variability and water mass distribution in the Iceland Sea, Quat. Sci. Rev., 23, 2247-2268, doi:10.1016/j.quascirev. 2004.08.002.

Eiríksson, J., K.-L. Knudsen, G. Larsen, J. Olsen, J. Heinemeier, H. B. BartelsJónsdóttir, H. Jiang, L. Ran, and L. A. Símonarson (2011), Coupling of palaeoceanographic shifts and changes in marine reservoir ages off north Iceland through the last millennium, Palaeogeogr. Palaeoclimatol. Palaeoecol., 302, 95-108, doi:10.1016/j.palaeo.2010.06.002.

Fichefet, T., and M. A. M. Maqueda (1997), Sensitivity of a global sea ice model to the treatment of ice thermodynamics and dynamics, J. Geophys. Res., 102(12), 12,609-12,646.

Flatau, M. K., L. Talley, and P. P. Niiler (2003), The North Atlantic Oscillation, surface current velocities, and SST changes in the subpolar North Atlantic, J. Clim., 16(14), 2355-2369, doi:10.1175/2787.1.

Gao, C., A. Robock, and C. Ammann (2008), Volcanic forcing of climate over the past 1500 years: An improved ice core-based index for climate models, J. Geophys. Res., 113, D23111, doi:10.1029/2008JD010239.

Hall, I. R., K. P. Boessenkool, S. Barker, I. N. McCave, and H. Elderfield (2010), Surface and deep ocean coupling in the subpolar North Atlantic during the last 230 years, Paleoceanography, 25, PA2101, doi:10.1029/ 2009PA001886.

Hanna, E., T. Jonsson, J. Olafsson, and H. Valdimarsson (2006), Icelandic coastal sea surface temperature records constructed: Putting the pulse on air-sea-climate interactions in the northern North Atlantic. Part I: Comparison with HadISST1 open-ocean surface temperatures and preliminary analysis of long-term patterns and anomalies of SSTs around Iceland, J. Clim., 19, 5652-5666, doi:10.1175/JCLI3933.1.

Hansen, B., and S. Østerhus (2000), North Atlantic-Nordic seas exchanges, Prog. Oceanogr., 45, 109-208, doi:10.1016/S0079-6611(99)00052-X.

Hatun, J., A. B. Sandø, H. Drange, B. Hansen, and H. Valdimarsson (2005), Influence of the Atlantic subpolar gyre on the thermohaline circulation, Science, 309, 1841-1844, doi:10.1126/science.1114777.

Haug, G. H., K. A. Hughen, D. M. Sigman, L. C. Peterson, and U. Röhl (2001), Southward migration of the intertropical convergence zone through the Holocene, Science, 293, 1304-1308, doi:10.1126/science.1059725.

Hopkins, T. S. (1991), The GIN-Sea-A synthesis of its physical oceanography and literature review 1972-1985, Earth Sci. Rev., 30, 175-318, doi:10.1016/0012-8252(91)90001-V

Hourdin, F., et al. (2006), The LMDZ4 general circulation model: Climate performance and sensitivity to parametrized physics with emphasis on tropical convection, Clim. Dyn., 27(7-8), 787-813, doi:10.1007/s00382006-0158-0 
Hurdle, B. G. (1986), The Nordic Seas, 777 pp., Springer, New York. Intergovernmental Panel on Climate Change (IPCC) (2007), Palaeoclimate, in Climate Change 2007: The Physical Science Basis: Contribution of Working Group I to the Fourth Assessment Report of the Intergovernmental Panel on Climate Change, edited by S. Solomon et al., chap. 6, pp. 433-497, Cambridge Univ. Press, Cambridge, U. K.

Jonsson, S., and H. Valdimarsson (2004), A new path for the Denmark strait overflow water from the Iceland Sea to Denmark Strait, Geophys. Res. Lett., 31, L03305, doi:10.1029/2003GL019214.

Kaufman, D. S., et al. (2009), Recent warming reverses long-term arctic cooling, Science, 325, 1236-1239, doi:10.1126/science.1173983.

Knudsen, K.-L., J. Eiríksson, H. Jiang, and I. Jónsdóttir (2009), Palaeoceanography and climate changes off north Iceland during the last millennium: Comparison of foraminifera, diatoms and ice-rafted debris with instrumental and documentary data, J. Quat. Sci., 24(5), 457-468, doi:10.1002/jqs.1292.

Krinner, G., N. Viovy, N. de Noblet-Ducoudre, J. Ogee, J. Polcher, P. Friedlingstein, P. Ciais, S. Sitch, and I. C. Prentice (2005), A dynamic global vegetation for studies of the coupled atmosphere-biosphere system, Global Biogeochem. Cycles, 19, GB1015, doi:10.1029/2003GB002199.

Lamb, H. H. (1965), The early medieval warm epoch and its sequel, Palaeogeogr. Palaeoclimatol. Palaeoecol., 1, 13-37, doi:10.1016/00310182(65)90004-0.

Lean, J. (2000), Evolution of the Sun's spectral irradiance since the Maunder Minimum, Geophys. Res. Lett., 27, 2425-2428, doi:10.1029/ 2000GL000043.

Lund, D. C., and W. Curry (2004), Late Holocene variability in Florida current surface density: Patterns and possible causes, Paleoceanography, 19, PA4001, doi:10.1029/2004PA001008

Lund, D. C., J. Lynch-Steiglitz, and W. Curry (2006), Gulf Stream density structure and transport during the past millennium, Nature, 444, 601-604, doi:10.1038/nature 05277

Madec, G., P. Delecluse, M. Imbard, and M. Levy (1998), OPA 8. 1 Ocean General Circulation Model Reference Manual: Note du Pole de Modélisation, Note 11, 91 pp., Inst. Pierre-Simon Laplace, Paris.

Malmberg, S. A. (1969), Hydrographic changes in the waters between Iceland and Jan Mayen in the last decade, Jöekull, 19, 30-43.

Mann, M. E., Z. H. Zhang, S. Rutherford, R. S. Bradley, M. K. Hughes, D. Shindell, C. Ammann, G. Faluvegi, and F. B. Ni (2009), Global signatures and dynamical origins of the Little Ice Age and Medieval Climate Anomaly, Science, 326, 1256-1260, doi:10.1126/science.1177303.

Marti, O., et al. (2010), Key features of the IPSL ocean atmosphere model and its sensitivity to atmospheric resolution, Clim. Dyn., 34, 1-26, doi:10.1007/s00382-009-0640-6.

Massé, G., S. Rowland, M.-A. Sicre, J. Jacob, E. Jansen, and S. Belt (2008), Abrupt climate changes for Iceland during the last millennium: Evidence from high resolution sea ice reconstructions, Earth Planet. Sci. Lett., 269, 565-569, doi:10.1016/j.epsl.2008.03.017.

Matthes, F. (1939), Report of committee on glaciers, Eos Trans. AGU, 20 , $518-523$.

McCave, I. N. (2005), Cruise Report RRS Charles Darwin 159: RAPID Climate Change, 49 pp., Univ. of Cambridge, Cambridge, U. K.

Mignot, J., M. Khodri, J. Servonnat, and C. Frankignoul (2011), Volcanic impact in the Atlantic oceanic circulation over the last millennium, Clim. Past Discuss., 7, 2511-2554, doi:10.5194/cpd-7-2511-2011.

Myneni, R. B., R. R. Nemani, and S. W. Running (1997), Estimation of global leaf area index and absorbed par using radiative transfer models, IEEE Trans. Geosci. Remote Sens., 35, 1380-1393, doi:10.1109/36.649788

Østerhus, S., W. R. Turell, S. Jonsson, and B. Hansen (2005), Measured volume, heat, and salt fluxes from the North Atlantic to the Arctic Mediterranean, Geophys. Res. Lett., 32, L07603, doi:10.1029/2004GL022188.

Prahl, F. G., and S. G. Wakeham (1987), Calibration of unsaturation patterns in long-chain ketone compositions for paleotemperature assessment, Nature, 330, 367-369, doi:10.1038/330367a0.

Prahl, F. G., L. A. Muehlhausen, and D. L. Zahnle (1988), Further evaluation of long-chain alkenones as indicators of palaeoceanographic conditions, Geochim. Cosmochim. Acta, 52, 2303-2310, doi:10.1016/0016-7037 (88)90132-9.

Rahmstorf, S. (2003), Thermohaline circulation: The current climate, Nature, 421, 699, doi:10.1038/421699a.

Ran, L., H. Jiang, K.-L. Knudsen, and J. Eiríksson (2011), Diatom-based reconstruction of palaeoceanographic changes on the north Icelandic shelf during the last millennium, Palaeogeogr. Palaeoclimatol. Palaeoecol., 302, 109-119, doi:10.1016/j.palaeo.2010.02.001.

Reimer, P. J., et al. (2009), IntCal09 and Marine09 radiocarbon age calibration curves, 0-50,000 years cal BP, Radiocarbon, 51, 1111-1150.

Richter, T. O., F. J. T. Peeters, and T. C. E. van Weering (2009), Late Holocene (0-2.4 ka BP) surface water temperature and salinity variability, Feni Drift, NE Atlantic Ocean, Quat. Sci. Rev., 28, 1941-1955, doi:10.1016/j. quascirev.2009.04.008

Robock, A. (2000), Volcanic eruptions and climate, Rev. Geophys., 38, 191-219, doi:10.1029/1998RG000054.

Schmidt, G. A., et al. (2011), Climate forcing reconstructions for use in PMIP simulations of the last millennium (v1.0), Geosci. Model Dev., 4, 33-45, doi:10.5194/gmd-4-33-2011.

Servonnat, J., P. Yiou, M. Khodri, D. Swingedouw, and S. Denvil (2010), Influence of solar variability, $\mathrm{CO}_{2}$ and orbital forcing between 1000 and $1850 \mathrm{AD}$ in the IPSLCM4 model, Clim. Past, 6, 445-460, doi:10.5194/cp-6-445-2010.

Sicre, M.-A., E. Bard, U. Ezat, and F. Rostek (2002), Alkenone distributions in the North Atlantic and Nordic sea surface waters, Geochem. Geophys. Geosyst., 3(2), 1013, doi:10.1029/2001GC000159.

Sicre, M.-A., J. Jacob, U. Ezat, S. Rousse, C. Kissel, P. Yiou, J. Eiríksson, K. L. Knudsen, E. Jansen, and J.-L. Turon (2008a), Decadal variability of sea surface temperatures off North Iceland over the last 2000 yrs, Earth Planet. Sci. Lett., 268, 137-142, doi:10.1016/j.epsl.2008.01.011

Sicre, M.-A., P. Yiou, J. Eiríksson, U. Ezat, E. Guimbaut, I. Dahhaoui, K. L. Knudsen, E. Jansen, and J.-L. Turon (2008b), A 4500-year reconstruction of sea surface temperature variability at decadal time scales off North Iceland, Quat. Sci. Rev., 27, 2041-2047, doi:10.1016/j.quascirev. 2008.08.009.

Skinner, L. C., and I. N. McCave (2003), Analysis and modeling of gravityand piston coring based on soil mechanics, Mar. Geol., 199, 181-204, doi:10.1016/S0025-3227(03)00127-0

Solanki, S. K., and N. A. Krivova (2006), Solar variability of possible relevance for planetary climates, Space Sci. Rev., 125, 25-37, doi:10.1007/ s11214-006-9044-7.

Stenchikov, G., T. L. Delworth, V. Ramaswamy, R. J. Stouffer, A. Wittenberg, and F. Zeng (2009), Volcanic signals in oceans, J. Geophys. Res., 114, D16104, doi:10.1029/2008JD011673.

Stuiver, M., and P. J. Reimer (1993), Extended ${ }^{14} \mathrm{C}$ database and revised CALIB 3.0 ${ }^{14} \mathrm{C}$ age calibration program, Radiocarbon, 35, 215-230.

Ternois, Y., M.-A. Sicre, and M. Paterne (2000), Climatic changes along the northwestern African continental margin over the last 30 kyrs, Geophys. Res. Lett., 27(1), 133-136, doi:10.1029/1999GL002306.

Timmreck, C., S. J. Lorenz, T. J. Crowley, S. Kinne, T. J. Raddatz, M. A. Thomas, and J. H. Jungclaus (2009), Limited temperature response to the very large AD 1258 volcanic eruption, Geophys. Res. Lett., 36, L21708, doi:10.1029/2009GL040083.

Valcke, S., L. Terray, and A. Piacentini (2000), Oasis 2.4, Ocean Atmosphere Sea Ice Soil: User's Guide, Tech. Rep. TR/CMGC/00/10, CERFACS, Toulouse, France.

Wang, Y.-M., J. L. Lean, and N. R. Sheeley Jr. (2005), Modeling the Sun's magnetic field and irradiance since 1713, Astrophys. J., 625, 522-538, doi:10.1086/429689.

Zangger, E., and I. N. McCave (1990), A redesigned Kasten core barrel and sampling technique, Mar. Geol., 94, 165-171, doi:10.1016/0025-3227 (90)90110-6.

J. Eiríksson, Earth Science Institute, University of Iceland, Askja, 101 Reykjavik, Iceland.

U. Ezat, M.-A. Sicre, and M.-X. Truong, Laboratoire des Sciences du Climat et de l'Environnement, IPSL-CNRS, Domaine du CNRS, Ave. de la Terrasse, F-91198 Gif-sur-Yvette CEDEX, France. (sicre@1sce.ipsl.fr)

I. R. Hall, School of Earth and Ocean Sciences, Cardiff University, Main Building, Park Place, Cardiff CF10 3AT, UK.

M. Khodri and J. Mignot, Laboratoire d'Océanographie et du Climat: Expérimentation et Approches Numériques, IPSL-UPMC/CNRS/IRD/ MNHN, 4 Pl. Jussieu, F-75252 Paris CEDEX, France.

K.-L. Knudsen, Department of Earth Sciences, University of Aarhus, DK-8000 Aarhus C, Denmark 